\title{
15. Urban traffic and health risk: what is the role for citizen participation in transport planning?
}

\author{
Marina van Geenhuizen and Anna Berti
} Suman

\subsection{INTRODUCTION}

One of the challenges of human scale urban planning, including transport, is that citizens feel more engaged and responsible for processes and outcomes of planning decisions, mainly in view of liveability of cities. This new engagement seems increasingly to be happening where traffic is at high volume and density, causing serious noise annoyance which may come with several health risks. These risks may include cardiovascular diseases such as hypertension, arteriosclerosis and ischaemic heart disease (Babisch, 2014; Basner et al., 2017). Addressing the issue of noise in urban traffic is not new. Some cities have already installed measurement systems to assess noise exposure for citizens. However, there is a more general trade-off in policy-making; for example, facilitating transport demand growth to promote economic development at the expense of noise exposure or low air quality for citizens. As a result, not much of the knowledge gained on citizens' exposure has been actually applied in urban policies for noise management.

In some cases, however, citizens have taken the initiative to measure and address high noise levels or other health risk by themselves, aimed at increasing quality of life in places that suffer from such risk (Goodchild, 2007). Such citizen initiatives can be called 'citizen sensing'. Citizen sensing initiatives have recently become increasingly popular, not only through improved sensor technology and mobile devices owned by citizens or collectively owned, but also, in particular situations, by a common feeling among citizens of distrust towards the actor(s) responsible for noise or low air quality (Gabrys et al., 2016; Berti Suman, 2018). Distrust may follow from the feeling of not being taken seriously; in particular, in calls for transparency in measurement undertaken by the responsible actor(s). Given these aspects, citizen sensing can 
be seen as a grassroots-driven initiative, not only aimed at improving understanding of the problem through measurement, but also taking steps towards reducing noise or other traffic annoyance.

In contrast, 'citizen science' is organized by established institutions, such as universities, to create or improve large-scale databases and modelling through the support of citizens (Berti Suman and Van Geenhuizen, 2019). Often involved with biodiversity cooperative studies, citizen science initiatives may also focus on high noise levels or any other traffic annoyance; however, in a more institutionalized way. In this context, we mention that terminology such as 'citizen sensing' and 'citizen science' is faced with blurring edges and swift changes. Accordingly, citizen sensing may also be seen as part of larger citizen science initiatives, referring to all participation of citizens (Eitzel et al., 2017; Heigl et al., 2019). In this vein, citizen science has been recognized as contributing both to scientific measurement and to policy-making (Van Brussel and Huyse, 2018). In more detail, Kullenberg and Kasperowski (2016) identify a strand within citizen science which is particularly overlapping with citizen sensing: namely, that related to the monitoring of health and quality of the environment. In this chapter, however, we draw a borderline between citizen sensing and citizen science.

The number of evaluation studies on influence of participatory citizen initiatives on urban planning solutions has remained small over the years. This situation may reflect various practical constraints to evaluation. For example, the aims of the participation are often not sufficiently clearly stated; the time dimension is difficult to take into account due to large time-lags; and the approach to evaluation may be an obstacle, due to an increased need for evaluating not only the end-results but also processes and new technology use underlying the end-results (e.g., Jiang et al., 2016). Accordingly, 'proofs' of evidence for benefits from participation tend to be limited to projects that are relatively simple, such as new bicycle lanes, or non-controversial, such as accessibility of buildings, such as shopping malls for wheelchair users (Kehayia et al., 2014).

In response to this, the chapter provides an approach to evaluation of citizen sensing/science by presenting a performance matrix. The approach draws on detailed case study results (Eisenhardt and Graebner, 2007; Emerson and Nabatchi, 2015), while the focus is on factors that influence how citizens' participation may contribute to solving urban transport problems. The research question is as follows: Which factors in citizen participation influence solutions to unwanted traffic impacts, and which work positively and which negatively in achieving such solutions?

In our contextualization of citizens' initiatives and design of the performance matrix, we draw on analysis of Amsterdam Schiphol Airport (AMS) (citizen sensing and noise) in the Netherlands and CuriousNoses in Antwerp/Flanders 
(citizen science and air quality) in Belgium. The case studies are part of a mixed data approach to grasp multifaceted dynamics and context-dependency. Thus, interviews were performed concerning citizens' participation in planning on bicycle lanes and functional change of city centres (Manchester, United Kingdom and Montreal, Canada), workshops included needs for and potentials of citizen initiatives, for example, 'Citizen Science - Gamma Radiation, Noise Annoyance and Air Quality' at the Netherlands Ministry of Infrastructure and Environment, November 2017, Utrecht (Netherlands), and 'Citizen Science and Environmental Monitoring: Benefits and Challenges', November 2018, Joint Research Centre, Ispra (Italy). Case literature included, for example, Carton and Ache (2017) on AMS, and Van Brussel and Huyse (2018) and Meysman and De Craemer (2018) on CuriousNoses, whereas detailed information on solutions was drawn from websites such as the Alderstafel advice (AMS) (Omgevingsraad Schiphol, 2020) and traffic measures in cities in Belgium (e.g., ELTIS, n.d.).

The chapter continues by highlighting societal trends that support the development of active participation by citizens (section 15.2). Attention then moves to a further conceptualization of citizen sensing and citizen science (section 15.3). In section 15.4, how this citizen participation has been applied is analysed in the two case studies. The performance matrix is presented and discussed in section 15.5. Section 15.6 concludes.

\subsection{TRENDS SUPPORTING CITIZENS' PARTICIPATION}

The emergence of citizen initiatives and the issue of citizen participation are rooted in or act in parallel with trends emerging since the mid-1990s (Nabatchi et al., 2017; Nesti, 2018). Firstly, there is the recognition of increased complexity and uncertainty in society, and the need for new qualities of local governance in solving urban problems and designing adequate services. Answers to such situations were already addressed in the seminal work of Ostrom (1990), emphasizing the need for co-production in an era of planning of urban services that was monopolized by officials, while users acted as passive consumers (e.g., Pestoff et al., 2012; Nesti, 2018). In the years that followed, active participation of citizens as users started to be seen as a way of increasing public service quality and delivery and, in a broader sense, as a kind of democratization of power and shift to participatory problem definition and solving (Emerson and Nabatchi, 2015; Ansell and Torfing, 2016; Holtmann and Rademacher, 2016). With the acceptance of active involvement of citizens (individuals/groups) in public service delivery and a route to active citizenship and communities (Osborne et al., 2016), policy-makers started to be regarded 
as having the important duty of understanding the needs of citizens as users, with concomitant influence on urban governance (Davidson et al., 2019).

Secondly, the increased attention for bottom-up initiatives and active citizen participation also fits two consecutive trends in science and knowledge production. One emerged in the early 1990s, when knowledge production tended to become more socially distributed, application-oriented, transdisciplinary, and subject to multiple accountability (Gibbons et al., 1994). The other one is more recent, bringing an even more prominent position of public sector and civic society actors in knowledge production, namely, as participants in solving societal challenges, including citizen science and open science (EC, 2014; Hecker et al., 2018). Accordingly, in a trend of democratization of science, citizens' influence has increased in agenda-setting in public research and participation in scientific data collection.

Thirdly, in the meantime, in innovation studies, users have become recognized as an important source of knowledge on innovation, with the customer active paradigm subsequently fostering various models of customer co-creation in the business sector (Prahalad and Ramaswamy, 2004; Kantola et al., 2014; Von Hippel, 2017). Likewise, citizens are increasingly considered as supportive in policy-making, by co-creation of practical solutions (OECD, 2020).

\subsection{CITIZEN SENSING AND CITIZEN SCIENCE}

In this section, we discuss the conceptualization of citizen sensing and citizen science in more detail. We emphasize that the terms are currently also used as popular buzzwords indicating many overlapping (grassroots-driven) practices, as well as shifts of terms between groups of actors involved (e.g., Turreira-Garcia et al., 2018). The discussion below evolves around origin and aim, and selection of participating citizens (Table 15.1).

Citizen sensing can be seen as an initiative of citizens (as lay people) who are triggered by their exposure to a risk (which may be a health risk) and intend to challenge the accountable actor(s) to recognize and solve the problem (Berti Suman and Van Geenhuizen, 2019; Berti Suman, 2020; Liu et al., 2014). The sense of being at risk, or the wish to gain a more immediate sense of environmental conditions (Gabrys, 2016, 2017), builds an urgent need among these citizens to access first-hand data on the problem situation. This holds true in particular if data from the actors causing the risk are not trusted by the citizens. As a result, citizens utilize networked sensor technology in measuring the exposure on their own account, thereby challenging institutional data (Boulos et al., 2011). With regard to participants' selection, self-selection takes place as layman and concerned people. Due to the grassroots and spontaneous character 
Table 15.1 Features of participatory initiatives: citizen sensing and citizen science

\begin{tabular}{lll}
\hline & Citizen sensing & Citizen science \\
\hline Origin/drive & - Distrust of institutional actor due & - Need for scientific data among insti- \\
& to information monopoly and low & tutional actors (university), sometimes \\
& transparency & along with public authorities \\
& - Emotional triggers from health risk & \\
Aim(s) & - Producing citizen-sensed valid data and & - Producing valid scientific data and \\
& visualization to challenge institutional & large-scale models; eventually inform \\
& data & public authorities in planning to reduce \\
& - Recognition of the health risk & negative impacts \\
& - Creating convergence and & - Creating trust in and credibility of data \\
& problem-solving & - Support to citizens in achieving behav- \\
& & ioural change \\
Selection of & - Self-selection as laymen concerned & - Selection often performed by institu- \\
citizens & about health risk, but question mark over & tional actor \\
& 'representativeness' & \\
\hline
\end{tabular}

Source: Adapted from Berti Suman and Van Geenhuizen (2019).

of the initiative (not planned by other actors), there may be a question mark concerning 'representativeness' of the citizens involved (Table 15.1).

Regarding the sensing component, various authors put emphasis on the need for producing high-quality data and maps, satisfying important data validity criteria as well as high resolution and ease of communication of real-time results, all of them increasing credibility and legitimacy (Keseru et al., 2019; Peckens et al., 2018). Other authors emphasize value added from deeper (contextual) understanding by citizens, as a result of their involvement in the practice of measurement. In the case of airports, this includes detailed information on the site of measurement, weather conditions (wind) and types of aeroplane causing peak noise (Gabrys et al., 2016; Jiang et al., 2016).

Citizen science can be described as the active participation of lay people in scientific research, often initiated by scientists and sometimes also by public authorities (Den Broeder et al., 2017). Citizen science tends to be more targeted to scientific data and knowledge production, rather than problem-solving or policy-making. The aim of citizen science can be understood as supplementing scientific analysis by measurement; for example, increasing detail in place (scale) and time, among others, to enable improved modelling. Many projects are in biodiversity research, such as monitoring bees for the sake of human subsistence, but also other species (Hallow et al., 2015; Cooper et al., 2017). An important supporting strategy in citizen science is building trust and credibility among citizens and among users in science on the quality of the data involved 
(Freitag et al., 2016). A secondary aim may be achieving steps towards mitigation or prevention of unwanted environmental impacts, among others by behavioural change of citizens. Further, unlike in citizen sensing, participants are often selected through an institutional procedure. While participation and co-creation by citizens tend to increase the legitimacy of the knowledge gained and solutions proposed, a nuance regarding the selection of participant citizens needs to be noted. Participants would often be 'the usual suspects', from the middle or rich class, well educated, already politically knowledgeable and highly sensitive to responsibility. Such a situation may weaken the legitimacy and democratic value of participation (Michels and De Graaf, 2017). Selection of participants and the connected data representativeness is a major concern for all participatory sensing initiatives (Keseru et al., 2019). What would be an appropriate principle for selection of citizens, however, is not clear, because of the many available principles, such as an appropriate range of (conflicting) interests in the process, sufficient representation of those who are affected by the risk, best quality data by educated (information and communication technology skills) citizens, and an easy-going process without delay, thereby excluding users with 'obstruction power' (Bryson et al., 2013).

\subsection{CASE STUDIES}

The analysis is centred on factors in citizen participation that contribute to reaching solutions to environmental risks. Both case studies - AMS and CuriousNoses - can be seen as representing successful developments, in that steps towards solutions have been taken, though the ways of doing so are different, and solutions may be temporary.

\subsubsection{Amsterdam Schiphol Airport: Citizen Sensing}

Amsterdam Schiphol Airport (AMS) is the main airport in the Netherlands and the third-largest in Europe for passenger transport, following London Heathrow and Paris/Charles de Gaulle (Eurostat, 2019). Today, 71 million passengers are handled at AMS per year (as of 2018). In the early 2000s, worried citizens launched a sensor system on noise in response to AMS's plans to create an additional runway (the fifth). The main complaint at that time was the dogmatic attitude and lack of transparency of the institutional (AMS) noise measurement system connected to an information monopoly, and lack of recognition of the health risk of (peaks in) noise annoyance (Carton and Ache, 2017; Berti Suman and Van Geenhuizen, 2019). Important steps towards solving the problem were recognition of the health risk and of the citizens' monitoring results, ultimately opening the door to constructive dialogue in co-production of practical solutions with the institutional actor 
AMS. In more detail, it appeared that strong performance factors have been the creation of a high-quality citizen monitoring system providing strong data validity and reliability that enabled contesting the information monopoly, and broader public and societal support through the adoption of this noise monitoring system even in other situations (for example, municipalities across the Netherlands).

Though causality cannot be proved, AMS decided in 2013 in collaboration with citizens and various authorities and governments to implement a plan to reduce and/or mitigate noise production. This plan on 'norms and maintenance' (Alderstafel, 2013) included selected runway use, specific flying techniques and routes for take-off and landing, preference in allocation of landing rights to airlines using relatively quiet and clean airplanes, and specific day/ night schedules. In addition, plans were made to mitigate ground noise from departures by specific landscaping (for example, noise-reflecting ridges).

The measures to be taken, however, do not limit growth in air traffic. It seems plausible that, when there is still room for mitigation or prevention of noise annoyance, citizen sensing may indeed work. This is particularly salient today with the national government's intention to increase the growth of air traffic above a limit that has been respected for several years, namely 500000 flights per year. When it comes to more drastic decisions, such as a halt to airport growth, room for citizens' input may be more limited.

\subsubsection{CuriousNoses: Citizen Science}

CuriousNoses (CN) started more recently (2017) and has been undertaken in cities in Flanders (Belgium), after a successful pilot in Antwerp. The scientific aim of $\mathrm{CN}$ is to accurately measure nitrogen dioxide $\left(\mathrm{NO}_{2}\right)$ concentration on a large scale that has never been done before, namely using 20000 measurement points (impossible without citizens' participation). The intention is in particular to test and increase the predictive capability of a more sophisticated model (ATMOSYS) that will inform policy-makers on air quality. Additional aims are to increase citizens' learning, and to inform and support citizens in behavioural change. In contrast to the AMS case, the project is rather institutionalized, initiated by the University of Antwerp and Flemish Environment Society, among others, and also including activity of the media (Meysman and De Craemer, 2018). The major task for participating citizens was fixing devices (tubes) on a street-facing window of their house measuring the concentration of $\mathrm{NO}_{2}$ in the ambient air. With almost 90 per cent of the measurements satisfying validity criteria, and with results indicating relatively high levels of $\mathrm{NO}_{2}$, such as in urban corridors between high buildings and near start-stop traffic at intersections, the project as a measurement project in environmental pollution can be considered an important achievement (META-EEB, 2018; De 
Standaard, 2019). As further results, the project has increased the plausibility and legitimacy of earlier measurements, and thereby could confirm policy urgency for authorities to reduce traffic.

It is noteworthy that at the start of the project there was already common ground for change, in which both design of urban traffic circulation plans and implementation of $\mathrm{CN}$ could be realized. The municipality of Ghent introduced a new traffic management plan in early 2017, that 'cuts' streets in the city centre to discourage all through traffic. In addition, the municipality of Antwerp in 2017 opted for a Low Emissions Zone that targets the most polluting vehicles, with most recently (early 2020) the introduction of more stringent norms (ELTIS, n.d.).

In a next stage of $\mathrm{CN}$ research, dynamic exposure of citizens to $\mathrm{NO}_{2}$ is measured, including exposure at home, at work and during home-to-work travelling. And finally, research will be carried out on societal benefits of the project, in terms of influence on the behaviour of the participating citizens and influence on the policies of local and regional authorities (CuriousNoses, 2019; De Standaard, 2019).

\subsection{PERFORMANCE MATRIX}

We develop a performance matrix by focusing on factors that influence how citizens' participation contributes to problem-solving of traffic annoyance that citizens experience. Before we discuss the different factors, we mention that it is difficult to reveal direct causality between citizens' sensing and achieving problem solutions. This can be illustrated with AMS, where citizens have been included with other actors on a board or platform that supported the comprehensive plan on norms and maintenance in 2013 (section 15.4), while other citizens remained sceptical and continued being active in measuring noise annoyance. This development points to a particular role of a narrow/ broad organizational layer between the citizen sensing activity and the design of envisaged solutions.

We distinguish five sets of factors, mainly inspired by citizen sensing initiatives because of their comprehensiveness: nature of the problem, organizational features of citizens, organizational features of the setting of public/ policy actors, actions/processes adequacy, and translation of measurement results into actionable solutions. In this way, we adopt and extend the approach by Emerson and Nabatchi (2015), Voorberg et al. (2015) and Berti Suman and Van Geenhuizen (2019), and acknowledge that factors may mutually interact and may change in the course of the process.

Table 15.2 displays the matrix, which we would qualify as preliminary, as it needs testing on main lines and requires refinement, using additional case studies, eventually on slightly different citizen participation. 
Table 15.2 Preliminary performance matrix

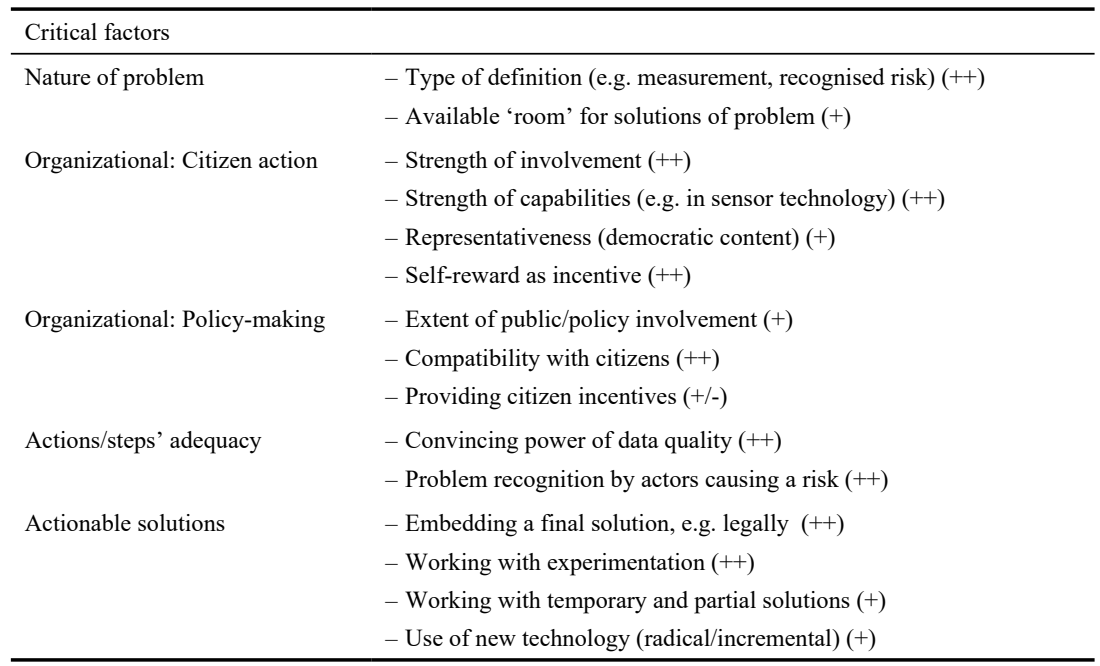

Note: Indicative strength, from modest (+/-) to very strong $(++)$.

On the problem side, we mention first the problem definition. If citizens or the driving organization define the problem as a measurement issue, the situation is different from solving a problem (for example, a health risk) that is initially not defined and recognized by actors causing the problem. If the problem definition is multisided, already accounting for complexity, it may support quickly reaching a beneficial solution. Conversely, if the problem definition is simplified, delay may arise. Next are strength of controversy and complexity, and room for solutions. If (actor) complexity is high and difficult to deal with, delay may happen and steps towards solutions may not be gained in the short term, or not at all. Also, if room for solutions is small in a situation of priority for traffic to grow, steps towards solutions tend to be more difficult to achieve.

On the organizational side concerning citizens, reaching beneficial solutions tends to critically depend on strong personal involvement (for example, connected to personal health risk), strong capabilities and strong representativeness of citizens for the problem situation. Furthermore, with regard to the organizational setting, there seems less direct influence by policy actors in citizen sensing in the beginning. Compatibility may increase in the course of the process when citizens and the responsible actor, as well as authorities/ policy-makers, have achieved common recognition of the problem and can work on constructive dialogue. In terms of incentives, self-reward for citizens through solving health risks seems to work stronger compared to any other incentive. 
Next, we address adequacy of actions/processes. As indicated above, well-running constructive processes are crucial for citizen sensing, such as creation of credibility, achieving common problem recognition (including recognition of citizens' data) and building constructive dialogue (Berti Suman and Van Geenhuizen, 2019). Strong adequacy is particularly important if citizens need to tackle large (dynamic multi-actor) complexity and uncertainty. We would qualify influence of the different adequacies as positive but also as negative, dependent on the situation. If adequacy is not sufficient, progress in building constructive relationships may be very slow.

And finally, we address translation into actionable solutions. Such translation is important as solutions often encompass much more than simply removing the cause of negative traffic impacts; for example, due to multi-causality, multi-actor interests and power, attention is needed to embed final solutions (e.g. in a legal sense), and to use experimentation and temporary and partial solutions as well as benefits from technology in the development of new solutions. In a negative situation, speed of action may be reduced by several years, if there is doubt about effectiveness of solutions, and extensive negotiation and experimentation need to be undertaken (such as two years of experiments in the case of AMS). It seems that citizen sensing is quite vulnerable to the influence of such factors. Using partial/temporary solutions, as well as experimentation and collective learning on novel solutions, such as in living labs (Van Geenhuizen, 2018; ELTIS, n.d.), may however limit the constraining influence. In addition, application of new technology in the solution seems important, and if incremental change is involved it may improve solutions' effectiveness. Application of radical solutions may work quicker but may also cause the risk of failure. Finally, what has been difficult to judge, and therefore has been excluded from our analysis (a study in itself), is how an additional organizational board (platform) may contribute to achieving solutions that are wanted by the citizens.

\subsection{CONCLUSION}

This chapter has explored evidence on problem-solving potentials of citizens' participation initiatives in urban transport planning. In particular, the chapter presented a performance matrix displaying mainly strong factors in achieving transport planning solutions. Strong influence tends to be exerted by characteristics of the problem; citizens' risk-based motivation, capabilities and representativeness; compatibility with the policy context (mainly in the later stages); and by adequacy in actions and processes. If the quality is high, such as through multi-sided problem definition, rich citizens' capabilities, multifaceted validity and coverage of data produced, and achieving problem recognition and constructive dialogue with actors/authorities, the contribution to 
beneficial solutions tends to be large. Furthermore, translation into actionable solutions comes with other questions, due to responding to needs for effectiveness and (legal) embedding, which may cause delay. All in all, factors that may be detrimental in reaching beneficial solutions for citizens include strong actor and other complexity (as a problem feature), priority for continued growth of traffic, and doubt about translation into actionable solutions.

The design of the matrix has been inspired mainly by a citizen sensing initiative. Regarding future research, there is the need for analysis of slightly different types of citizen participation, with the aim of testing and refining the matrix. In detail, there is the need to learn more about data validity and selection bias of participating citizens, motivation of citizens to participate, as well as citizen selection criteria that would be adequate in different problem and organizational settings. Positive influence of the establishment of boards and platforms could also be the subject of further research.

\section{REFERENCES}

Alderstafel (2013). Norms and maintenance. https://www.omgevingsraadschiphol.nl/ adviezen-alderstafel/ (accessed: 3 January 2020).

Ansell, C., and Torfing, J. (2016). Handbook of Theories of Governance. Cheltenham, UK and Northampton, MA, USA: Edward Elgar Publishing.

Babisch, W. (2014). Updated exposure-response relationship between road traffic noise and coronary heart diseases: a meta-analysis. Noise and Health, 16(68), 1-9.

Basner, M., Clark, C., and Hansell, A. (2017). Aviation noise impacts: state of the science. Noise and Health, 19(87), 41-50.

Berti Suman, A. (2018). The smart transition: an opportunity for a sensor-based public-health risk governance? International Review of Law, Computers and Technology, 32(2-3), 257-274.

Berti Suman, A. (2020). Sensing the risk. In search of the factors contributing to the policy uptake of citizen sensing. PhD thesis, Tilburg University.

Berti Suman, A., and Van Geenhuizen, M. (2019). Not just noise monitoring: rethinking Citizen Sensing for risk-related problem-solving. Journal of Environmental Planning and Management, 63(3), 546-567.

Boulos, K.B., Resch, B., Crowley, D.N., Breslin, J.G., Sohn, G., et al. (2011). Crowdsourcing, citizen sensing and sensor web technologies for public and environmental health surveillance and crisis management: trends, OGC standards and application examples. Journal of Health Geographics, 10(67), 67-96.

Bryson, J.M., Quick, K.S., Slotterback, C.S., and Crosby, B.C. (2013). Designing public participation processes. Public Administration Review, 73(1), 23-34.

Carton, L.J., and Ache, P.M. (2017). Citizen-sensor-networks to confront government decision-makers: two lessons from the Netherlands. Journal of Environmental Management, 196, 234-251.

Cooper, C., Larson, L., Holland, K.K., Gibson, R., Farnham, D., et al. (2017). Contrasting the views and actions of data collectors and data consumers in a volunteer water quality monitoring project: implications for project design and management. Citizen Science: Theory and Practice, 2(1), 1-14. 
CuriousNoses (2019). (in Dutch) CuriousNoses produce data on actual (dynamic) exposure. Antwerp University. https://www.uantwerpen.be/nl/centra/imdo/onderzoek/ curieuzeneuzen-2019/ (accessed: 2 March 2020).

Davidson, K., Coenen, L., Acuto, M., and Gleeson, B. (2019). Reconfiguring urban governance in the age of rising city networks: a research agenda. Urban Studies, 56(16), 3540-3555.

De Standaard (2019). CurieuzeNeuzen Vlaanderen. https://www.standaard.be/ curieuzeneuzen (accessed: 10 December 2019).

Den Broeder, L., Lemmens, L., Uysal, S., Kauw, K., Weekenborg, J., et al. (2017). Public health citizen science; perceived impacts on citizen scientists: a case study in a low-income neighbourhood in the Netherlands. Citizen Science: Theory and Practice, 2(1), 1-17.

Eisenhardt, K., and Graebner, M. (2007). Theory-building from cases: opportunities and challenges. Academy of Management Journal, 50(1), 25-32.

Eitzel, M.V., Cappadonna, J.L., Santos-Lang, C., Duerr, R.E., Virapongse, A., et al. (2017). Citizen science terminology matters: exploring key terms. Citizen Science: Theory and Practice, 2(1). http://doi.org/10.5334/cstp.96.

ELTIS (Urban Mobility Observatory) (n.d.). https://eltis.org (accessed: 8 August 2020).

Emerson, K., and Nabatchi, T. (2015). Evaluating the productivity of collaborative governance regimes: a performance matrix. Public Performance and Management Review, 38, 717-747.

European Commission (EC) (2014). Background Document Public Consultation 'Science 2.0': Science in Transition. Brussels: EC.

Eurostat (2019), News release, 186/2019.

Freitag, A., Meyer, R., and Whiteman, L. (2016). Strategies employed by citizen science programs to increase the credibility of their data. Citizen Science: Theory and Practice, 1(1), 1-11.

Gabrys, J. (2016). Practicing, materialising and contesting environmental data. Big Data and Society, 3(2), 1-7.

Gabrys, J. (2017). Citizen sensing, air pollution and fracking: from 'caring about your air' to speculative practices of evidencing harm. Sociological Review, 65, 172-192.

Gabrys, J., Pritchard, H., and Barratt, B. (2016). Just good enough data: Figuring data citizenships through air pollution sensing and data stories. Big Data and Society, $3(2), 1-14$.

Gibbons, M., Limoges, C., Nowotny, H., Schwartzman, S., Scott, P., and Trow, M. (1994). The New Production of Knowledge. The Dynamics of Science and Research in Contemporary Societies. London: SAGE Publications.

Goodchild, M. (2007). Citizens as sensors: the world of volunteered geography. GeoJournal, 69(4), 211-221.

Hallow, B., Roetman, P., Walter, M., and Daniels, C. (2015). Citizen Science for policy development: The case of koala management in South Australia. Environmental Science and Policy, 47, 126-136.

Hecker, S., Haklay, M., Bowser, A., Makuch, Z., and Vogel, J. (eds) (2018). Citizen Science: Innovation in Open Science, Society and Policy. London: UCL Press.

Heigl, F., Kieslinger, B., Paul, K.T., Uhlik, J., and Dörler, D. (2019). Opinion: toward an international definition of citizen science. PNAS, 116(17), 8089-8092.

Holtmann, E., and Rademacher, C. (2016). Decentralization of power and of decision-making - an institutional driver for systems change to democracy. Historical Social Research, 41(3), 281-298. 
Jiang, Q., Kresin, F., Bregt, A.K., Kooistra, L., Pareschi, E., et al. (2016). Citizen sensing for improved urban environmental monitoring. Journal of Sensors, 1-9. https://doi.org/10.1155/2016/5656245.

Kantola, T., Hirvikoski, T., Lehto, P., Aholaakko, T.K., Kukkonen, M.L., and Partamies, S. (2014). Towards co-creation of ehealth services. Interdisciplinary Studies Journal, 3, 192-205.

Kehayia, E., Swaine, B., Longo, C., Ahmed, S., Archambault, P., Fung, J., et al. (2014). Creating a rehabilitation living lab to optimize participation and inclusion for persons with physical disabilities. Alter, 8(3), 151-157.

Keseru, I., Wuytens, N., and Macharis, C. (2019). Citizen observatory for mobility: a conceptual framework. Transport Reviews, 39(4), 485-510.

Kullenberg, C., and Kasperowski, D. (2016). What is citizen science? A scientometric meta-analysis. PLoS ONE, 11(1). https://doi.org/10.1371/journal.pone.

Liu, H.-Y., Kobernus, M., Broday, D., and Bartonova, A. (2014). A conceptual approach to a citizens' observatory - supporting community-based environmental governance. Environmental Health, 13(107), 1-13.

META-EEB (Europe Environmental Bureau) (2018). https://www.meta.eeb.org/2018/ 10/04/five-things-we-learnt-when-20000-belgians-became-air-pollution-scientists/ (accessed: 2 March 2020).

Meysman, F., and De Craemer, S. (2018), CuriousNoses Vlaanderen: report on data (in Dutch). University of Antwerp.

Michels, A., and De Graaf, L. (2017). Examining citizen participation: local participatory policy-making and democracy revisited. Local Government Studies, 43(6), 875-881.

Nabatchi, T., Sancino, A., and Sicilia, M. (2017). Varieties of participation in public services: the who, when, and what of coproduction. Public Administration Review, 77, 766-776.

Nesti, G. (2018). Co-production for innovation: the urban living lab experience. Policy and Society, 37(3), 310-325.

OECD (2020). Innovative Citizen Participation and New Democratic Institutions. Paris: OECD.

Omgevingsraad Schiphol (2020). Schiphol Environment Council (Omgevingsraad Schiphol platform). https://www.omgevingsraadschiphol.nl.

Osborne, S.P., Radnor, Z., and Strokosch, K. (2016). Co-production and the co-creation of value in public services: a suitable case for treatment? Public Management Review, 18(5), 639-653.

Ostrom, E. (1990). Governing the Commons: The Evolution of Institutions for Collective Action. New York: Cambridge University Press.

Peckens, C., Porter, C., and Rink, T. (2018). Wireless sensor networks for long-term monitoring of urban noise. Sensors, 18(9), 3161.

Pestoff, V., Brandsen, T., and Verschuere, B. (2012). New Public Governance, the Third Sector and Coproduction. London: Routledge.

Prahalad, C.K. and Ramaswamy, V. (2004). Co-creation experiences: the next practice in value creation. Journal of Interactive Marketing, 18(3), 6-14.

Turreira-García, N., Lund, J.F., Domínguez, P., Carrillo-Anglés, E., Brummer, M.C., et al. (2018). What is in a name? Unpacking 'participatory' environmental monitoring. Ecology and Society, 23(2). https://doi.org/10.5751/ES-10144-230224.

Van Brussel, S., and Huyse, H. (2018). Citizen science on speed? Realising the triple objective of scientific rigour, policy influence and deep citizen engagement in 
a large-scale citizen science project on ambient air quality in Antwerp. Journal of Environmental Planning and Management, 62(3), 535-551.

Van Geenhuizen, M. (2018). A framework for the evaluation of living labs as boundary spanners in innovation. Environment and Planning C, Politics and Space, 36(7), $1280-1298$.

Von Hippel, E. (2017). Free Innovation: How Citizens Create and Share Innovations. Cambridge, MA: MIT Press.

Voorberg, W.H., Bekkers, V.J.J.M., and Tummers, L.G. (2015). A systematic review of co-creation and co-production. Public Management Review, 17(9), 1333-1357. 